\title{
A Case of Partial Short Arm Deletion in Chromosome 9 with Inguinal Hernia, Testicular Cystic Lesion, and Arthrogryposis Multiplex Congenita
}

Eun Jeong Kim, M.D., Sung-Hoon Chung, M.D., Tae Sung Park, M.D.*, and Yong-Sung Choi, M.D. Departments of Pediatrics and Laboratory Medicine*, Kyung Hee University School of Medicine, Seoul, Korea

\section{ABSTRACT}

Chromosome 9p syndrome is a rare chromosomal abnormality caused by a partial deletion in chromosome 9. It was first described in 1973 by Alfi et al., and has since been shown to have diverse clinical phenotypes. Here, we reported a case of a male infant with joint contracture of the extremities, dysmorphic face, inguinal hernia, and testicular cystic masses. Chromosomal analysis revealed a terminal deletion at the short arm of chromosome 9. The major clinical features of the 9p deletion syndrome are trigonocephaly, small palpebral fissures, a flat nasal bridge, and mental retardation. To the best of our knowledge, this is the first reported case of a patient with 9p24 deletion presenting with arthrogryposis multiplex congenita.

Key Words: Short arm deletion, Chromosome 9, Inguinal hernia, Arthrogryposis

\section{INTRODUCTION}

The chromosome 9p deletion syndrome was first reported in 1973 by Alfi et al. ${ }^{1)}$, and has since been reported worldwide. It is caused by the partial deletion of the short arm of chromosome 9 , and is clinically characterized by trigonocephaly with a prominent forehead, small palpebral fissures, a flat nasal bridge, posteriorly angulated ears, micrognathia, anteverted nostrils, a long philtrum, and hypotonia ${ }^{2,3)}$. In some cases, congenital malformations such as cardiac defects, inguinal hernia, omphalocele, and choanal atresia have been found ${ }^{4}$. The clinical manifestations of this syndrome are diverse, and depend on the extent and location of the deletion.

Patients who have the 9p deletion as well as the $46, \mathrm{XY}$ chromosomal disorder have shown abnormal sexual development ${ }^{5,6)}$. The gonadal phenotype appears in the form of complete gonadal dysgenesis, hypospadias, cryptorchidism, and/or gonadoblastoma ${ }^{7,8)}$. The external genital expression varies from complete female to male with hypospadias ${ }^{6,9)}$.

Abnormal muscle tone, mainly hypohonia, has been observed in some patients with the 9 p24 deletion syndrome ${ }^{10)}$. However, arthrogryposis multiplex congenita (AMC) has not been reported in any case of 9p24 deletion. AMC is characterized by contractures in more
Received: 24 April 2017

Revised: 13 May 2017

Accepted: 15 May 2017

Correspondence to: Yong-Sung Choi Department of Pediatrics, Kyung Hee University School of Medicine, 23 Kyungheedae-ro, Dongdaemun$\mathrm{gu}$, Seoul 02447, Korea

Tel: +82-2-958-8279

Fax: +82-2-958-8304

E-mail: feelhope@khu.ac.kr

\footnotetext{
Copyright(c)

By Korean Society of Neonatology.

All right reserved.

This is an Open-Access article distributed under the terms of the Creative Commons Attribution Non-Commercial License (http://creativecommons.org/licenses/ by-nc/4.0), which permits unrestricted non-commercial use, distribution, and reproduction in any medium, provided the original work is properly cited.
} 
than two joints, and is thought to be caused by both genetic and environmental factors ${ }^{11)}$. To the best of our knowledge, this is the first reported case of a patient with 9p24 deletion presenting with AMC.

\section{CASE REPORT}

A male neonate with contracture of both extremities was admitted at our center for evaluation and management on the second day after birth. He was born at full term from nonconsanguineous parents by spontaneous vaginal delivery. At birth, he weighed $3.65 \mathrm{~kg}$ (50th-75th percentile). He had an unremarkable family history, and all antenatal scans were normal. On physical examination, he had dry and scaly skin reminiscent of ichthyosis, systolic murmur, and dysmorphic features such as a flat occiput, low-set ears, a flat nasal bridge, and hyperteloism. Flexion contractures were observed on the knees $\left(60^{\circ}\right)$, elbows $\left(150^{\circ}\right)$, and wrists $\left(130^{\circ}\right)$. Initially, he had normal male external genitalia without inguinal hernia (Figure 1).

On the day of admission, his laboratory results were as follows: leukocyte count: 14,370/ $\mathrm{mm}^{3}$, hemoglobin level: $20.8 \mathrm{~g} /$ dL, platelet count: $299,000 / \mathrm{mm}^{3}$, serum total bilirubin level: $12.3 \mathrm{mg} / \mathrm{dL}$, conjugated bilirubin level: $0.5 \mathrm{mg} / \mathrm{dL}$, aspartate transaminase level: $84 \mathrm{U} / \mathrm{L}$, alanine aminotransferase level: 23 U/L, and gamma glutamyl transferase level: 166 U/L. Serum values of protein, albumin, and electrolytes were all in the normal range. Prothrombin time (13.3 s) and activated partial

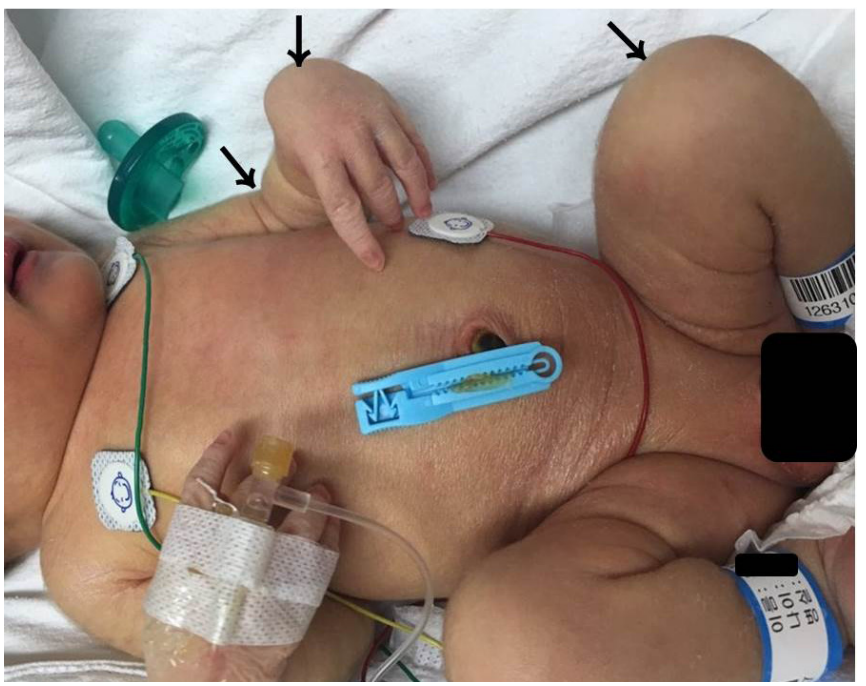

Figure 1. Image of arthrogryposis on admission. Arrows indicate flexion contractures of the left knee, elbow, and wrist. thromboplastin time (38.9 s) were not prolonged. Serological investigations for hepatitis and congenital infections returned negative results. Thyroid function test results were within the normal range. The results of an abdominal ultrasound suggested physiological hydronephrosis in both kidneys. Brain ultrasound, echocardiographic study, and brainstem auditory- evoked potential analysis all revealed normal findings. Based on these findings, the patient was assumed to have the AMC syndrome. After prescribing rehabilitation medicine, he was administered splints for knees and wrists, and his parents were educated about stretching exercises. He was discharged with a continuous rehabilitation treatment plan.

Chromosome microarray analysis revealed a $14.2-\mathrm{Mb}$ deletion, at 9p24.3p22.3 (208, 454-14, 138, 378)×1 (Figure 2). Karyotyping was performed for the parents as well, to help with their genetic counseling. Chromosomal analysis of the parents

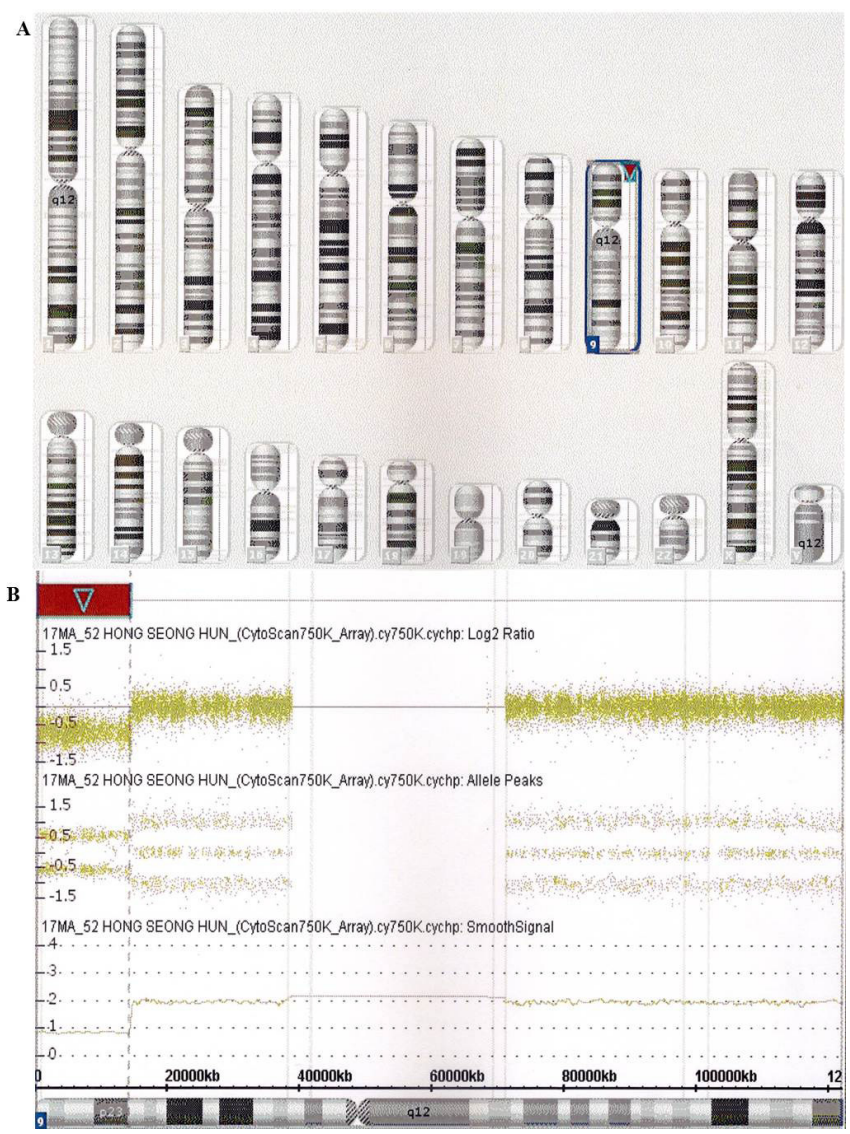

Figure 2. Peripheral blood chromosome microarray. (A) Karyotyping indicates terminal deletion of the short arm of chromosome 9. (B) Patient has a 14.2-Mb deletion on the terminal short arm of chromosome 9p24.3p22.3. Red triangles at chromosome 9 indicate the breakpoints. 

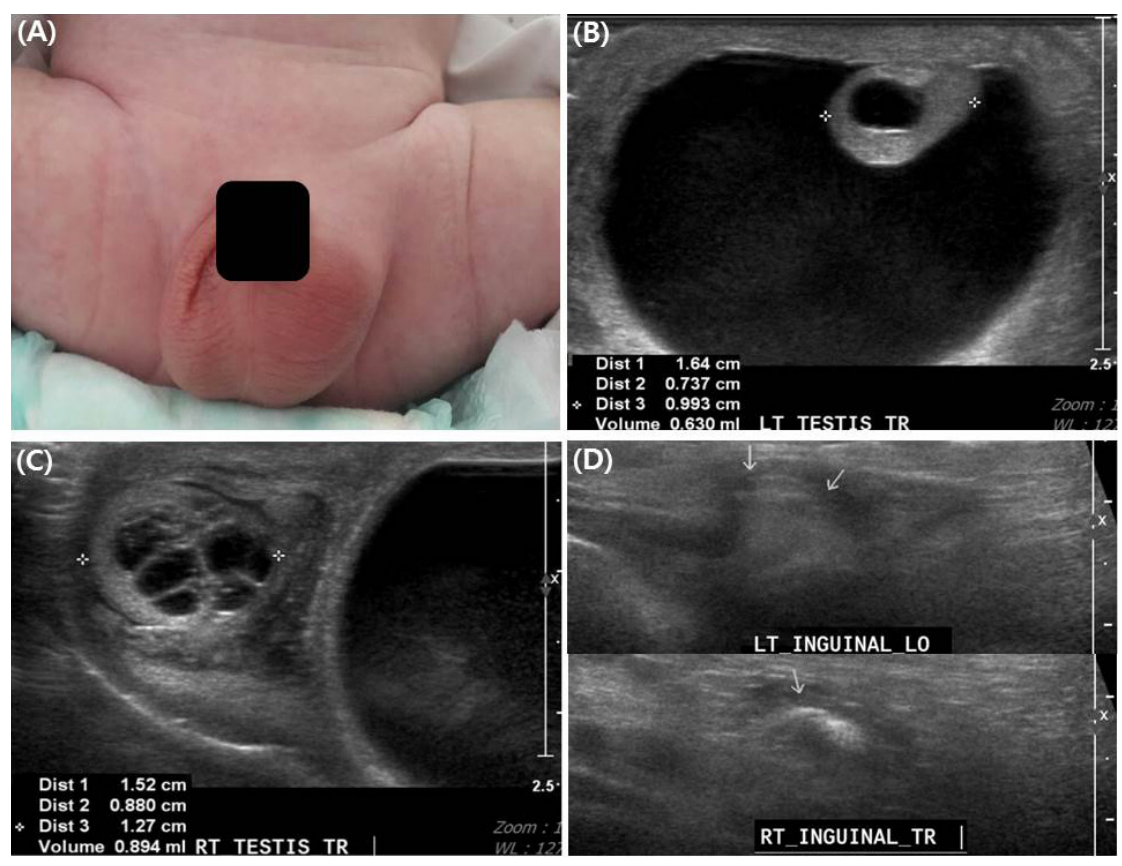

Figure 3. External genitalia and scrotal sonography images. (A) Image of indirect inguinal hernia. (B) Cystic lesion on the hydrocele within the left testis on a scrotal sonography scan. (C) Multilocular cystic lesion within the right testis on scrotal sonography scan. (D) Both inguinal hernias appearing on the scrotal sonography scan.

returned normal results, suggesting that the deletion was de novo. After performing stretching exercises for 4 weeks, the patient was able to fully extend both elbow and wrist joints, and showed improved extension of the knee joints. At one month of age, a left inguinal hernia was observed (Figure 3), which gradually increased in size. Scrotal ultrasound revealed a large left hydrocele, both indirect inguinal hernias, and bilateral intratesticular multilocular cystic lesions (right >left) (Figure 3). Tumor markers were analyzed to rule out tumorous conditions. Serum alpha-fetoprotein level was $1,162 \mathrm{ng} / \mathrm{mL}$, and betahuman chorionic gonadotropin level was $1.2 \mathrm{mIU} / \mathrm{mL}$. As the possibility of a malignancy was considered low, the decision was made for the patient to undergo observations and follow up at an outpatient clinic. When the patient was 58 days old, the splint treatment was deemed no longer necessary, and only the stretching exercises were continued. Because growth retardation, developmental delay, and cognitive impairment are common in patients with $9 \mathrm{p}$ terminal deletion syndrome, he is undergoing close developmental evaluation.

\section{DISCUSSION}

The phenotypes observed in this case were consistent with those of other previously reported patient with $9 p$ deletion syndrome ${ }^{6,7,12)}$. In addition, our patient showed symptoms of AMC, which have not previously been reported in patients with de novo 9p deletion syndrome. Various studies have reported that $9 p$ deletion syndrome is caused by a partial monosomy of 9p, with breakpoint sites mainly in the regions 9p22 to 9p24 In this case, deletion of regions 9p22.3 to 9p24 was confirmed by chromosomal microarray. This region contains many critical genes, including DMRT1-3, DOCK8, KANK1, SMARCA2, VLDLR, KCNV2, GLIS3, SLC1A1, JAK2, GLDC, TYRP1, CER1, and MPDZ (OMIM).

Haploinsufficiency of the sex-determining genes, DMRT1 and 2, which are located on 9p24.3, and other genetic defects are likely associated with the abnormal sexual development ${ }^{10)}$. DMRT1 activates testis-specific genes such as Sox9 and Sox8, and represses ovary-specific genes encoding Fox12, Wnt4 and R-spondin-1 signaling proteins, and estrogen receptors ${ }^{2,5,7)}$. CER1 has been proposed as a candidate gene responsible for dysmor- 
phic face syndromes, including trigonocephalya ${ }^{10)}$. Although we did not determine the exact mechanism here, deletion of these genes might have contributed to the phenotype of our patient.

AMC is characterized by contractions of multiple joints at the time of birth. The precise cause of AMC is not known. Recently, advances in molecular genetics have made it possible to understand the mechanisms of the pathogenesis of AMC. For instance, arthrogryposis multiplex congenital distal-1 (AMCD1) has been shown to be associated with a mutation in the TPM2 gene, located at $9 \mathrm{p} 13.3^{10}$. However, there have been no reports of an association between AMC and terminal 9p deletion syndrome; furthermore, the contractures of the hand and foot joints, whitch are often seen in AMCD-1, were not seen in our patient. We concluded that AMC might be a new phenotype associated with unidentified genes in the 9p22.3-9p24 region.

Despite many efforts, clear genotype/phenotype correlations have not been established, mainly due to the high variation of phenotypes in patients with 9p deletions. Future studies of the roles of genes involved in the $9 p$ terminal deletion syndrome are needed.

\section{REFERENCES}

1) Alfi O, Donnell GN, Crandall BF, Derencsenyi A, Menon R. Deletion of the short arm of chromosome no.9 (46,9p-): a new deletion syndrome. Ann Genet 1973;16:17-22.

2) Huret JL, Leonard C, Forestier B, Rethore MO, Lejeune J. Eleven new cases of del(9p) and features from 80 cases. J Med Genet 1988;25:741-9.

3) Sirisena ND, Wijetunge UK, de Silva R, Dissanayake VH. Child with deletion 9p syndrome presenting with craniofacial dys- morphism, developmental delay, and multiple congenital malformations. Case Rep Genet 2013;2013:785830.

4) Swinkels ME, Simons A, Smeets DF, Vissers LE, Veltman JA, Pfundt R, et al. Clinical and cytogenetic characterization of 13 Dutch patients with deletion 9p syndrome: delineation of the critical region for a consensus phenotype. Am J Med Genet A 2008;146a:1430-8.

5) Bennett CP, Docherty Z, Robb SA, Ramani P, Hawkins JR, Grant D. Deletion 9p and sex reversal. J Med Genet 1993;30:518-20.

6) McDonald MT, Flejter W, Sheldon S, Putzi MJ, Gorski JL. XY sex reversal and gonadal dysgenesis due to $9 \mathrm{p} 24$ monosomy. Am J Med Genet 1997;73:321-6.

7) Christ LA, Crowe CA, Micale MA, Conroy JM, Schwartz S. Chromosome breakage hotspots and delineation of the critical region for the 9p-deletion syndrome. Am J Hum Genet 1999; 65:1387-95.

8) Mroczek M, Kabzinska D, Chrzanowska KH, Pronicki M, Kochanski A. A novel TPM2 gene splice-site mutation causes severe congenital myopathy with arthrogryposis and dysmorphic features. J Appl Genet 2017;58:199-203.

9) Murphy MW, Sarver AL, Rice D, Hatzi K, Ye K, Melnick A, et al. Genome-wide analysis of DNA binding and transcriptional regulation by the mammalian Doublesex homolog DMRT1 in the juvenile testis. Proc Natl Acad Sci U S A 2010;107:13360-5.

10) Barbaro M, Balsamo A, Anderlid BM, Myhre AG, Gennari M, Nicoletti A, et al. Characterization of deletions at $9 p$ affecting the candidate regions for sex reversal and deletion $9 \mathrm{p}$ syndrome by MLPA. Eur J Hum Genet 2009;17:1439-47.

11) Del Rey G, Venara M, Papendieck P, Gruñeiro L, Tangari A, Boywitt A, et al. Association of distal deletion of the short arm of chromosome 9 with $46, \mathrm{XY}$ disorder of sex development and gonadoblastoma. Biol Syst Open Access 2015;4:1-3.

12) Matson CK, Murphy MW, Sarver AL, Griswold MD, Bardwell VJ, Zarkower D. DMRT1 prevents female reprogramming in the postnatal mammalian testis. Nature 2011;476:101-4. 